\title{
Mesoporous transition alumina with uniform pore structure synthesized by alumisol spray pyrolysis
}

\author{
Chang Liu, Yongchun Liu, Qingxin Ma, Hong He* \\ State Key Laboratory of Environmental Chemistry and Ecotoxicology, Research Center for Eco-Environmental Sciences, Chinese Academy of Sciences, Beijing 100085, China
}

\section{A R T I C L E I N F O}

\section{Article history:}

Received 20 April 2010

Received in revised form 12 July 2010

Accepted 20 July 2010

\section{Keywords:}

Mesoporous transition alumina

Pore structure

Alumisol

Spray pyrolysis

Thermal stability

\begin{abstract}
A B S T R A C T
Mesoporous transition alumina was prepared by spray pyrolysis of an alumisol precursor, without the use of structure-directing reagents. The prepared alumina exhibited a well-defined mesoporous structure with narrow pore size distribution $(3.0-4.7 \mathrm{~nm})$. Preparation temperature played a major role in the phase formation and the porosity of prepared alumina. The phase transformation of boehmite to $\gamma-\mathrm{Al}_{2} \mathrm{O}_{3}$ and $\theta$ $\mathrm{Al}_{2} \mathrm{O}_{3}$ was observed at 800 and $1200^{\circ} \mathrm{C}$, respectively. An increase in preparation temperature resulted in a decrease in surface area and pore volume and an increase in pore size. Longer residence time promoted the crystallinity of prepared alumina effectively, but it also led to the formation of particles with smaller surface area, lower pore volume, larger pore size, and broader pore size distribution. Additionally, while alumisol concentration had little effect on the surface area, its reduction led to a decrease in pore volume and pore size and caused the formation of bimodal pore size distribution. The as-prepared alumina also exhibited excellent thermal stability, showing great application potential for industry.
\end{abstract}

(C) 2010 Elsevier B.V. All rights reserved.

\section{Introduction}

Thermal decomposition of various aluminum hydrates yields a number of crystalline variations of alumina, defined as transition aluminas [1]. Due to their particular structural and morphological properties, transition aluminas have been applied widely in the catalysis field [2-4]. The performance of conventional alumina is, however, frequently limited due to uncontrolled porosity, which induces deactivation by coking and plugging and hinders the diffusion of reactants and products [5-7]. Most catalysts based on mesostructured alumina exhibit higher catalytic activity than those based on conventional alumina [8-10]. For instance, the mesoporous alumina supported $\mathrm{MoO}_{3}$ catalysts are almost two times more active than the conventional commercial $\mathrm{MoO}_{3} / \mathrm{Al}_{2} \mathrm{O}_{3}$ catalyst in thiophene hydrodesulfurization reaction [11]. Preparation of alumina with high surface area, uniform pore structure and narrow pore size distribution is, therefore, of tremendous interest for both technological applications and fundamental research. As an extension of the synthesis of mesoporous silica and mesoporous aluminosilicates [12], aluminas with ordered mesopores are commonly prepared from self assembly based on sol-gel processes in the presence of templates. This synthesis method consists of multistep procedures including hydrolysis and condensation, filtration and washing, and calcination to remove surfactants [13-17]. Whereas, the collapse of the mesostructure after calcination [18,19], the high

\footnotetext{
* Corresponding author. Tel.: +86 10 62849123; fax: +8610 62923563.

E-mail address: honghe@rcees.ac.cn (H. He).
}

cost of additives, and the complexity of the multistep process limits the practical application of present synthesis approaches.

Spray pyrolysis, a widely used method for powder generation in industry [20,21], possesses good flexibility and industrial viability in the preparation of conventional alumina. In this method, atomized droplets of a precursor solution undergo evaporation and shrinkage while flowing through a high temperature reactor, and eventually form solid particles. Previous researches on the preparation of alumina by spray pyrolysis mainly focused on the effects of the precursor solution, as well as other experimental conditions on the morphology [22-25] and phase transformation behavior of products [26-28]. For example, when different kinds of inorganic and metallo-organic alumina sources were used as precursor solutions, alumina particles with different morphologies were generated, including spherical [22,23], hollow [24], or doughnut-like [25]. In contrast to morphology, the porosity of alumina prepared by spray methods has received little attention. Boissière et al. [29] applied the spray drying method to prepare alumina mesoporous spheres using $\mathrm{AlCl}_{3} \cdot 6 \mathrm{H}_{2} \mathrm{O}$ as the $\mathrm{Al}$ precursor and $[\mathrm{E}(\mathrm{B})]_{75}-[\mathrm{EO}]_{86}$ block copolymer as the templating agent. Additionally, Kim et al. [30] prepared mesoporous alumina particles via spray pyrolysis using $\mathrm{Al}(\mathrm{NO})_{3} \cdot 9 \mathrm{H}_{2} \mathrm{O}$ and cetyltrimethylammonium bromide (CTAB) as the $\mathrm{Al}$ precursor and pore directing agent, respectively. The formation of mesostructures in these synthesis processes was attributed to the use of structure-directing reagents, however, which may limit practical application due to production costs. Furthermore, the incomplete decomposition of the additives and residue of aluminum salts may result in impurely produced alumina. 

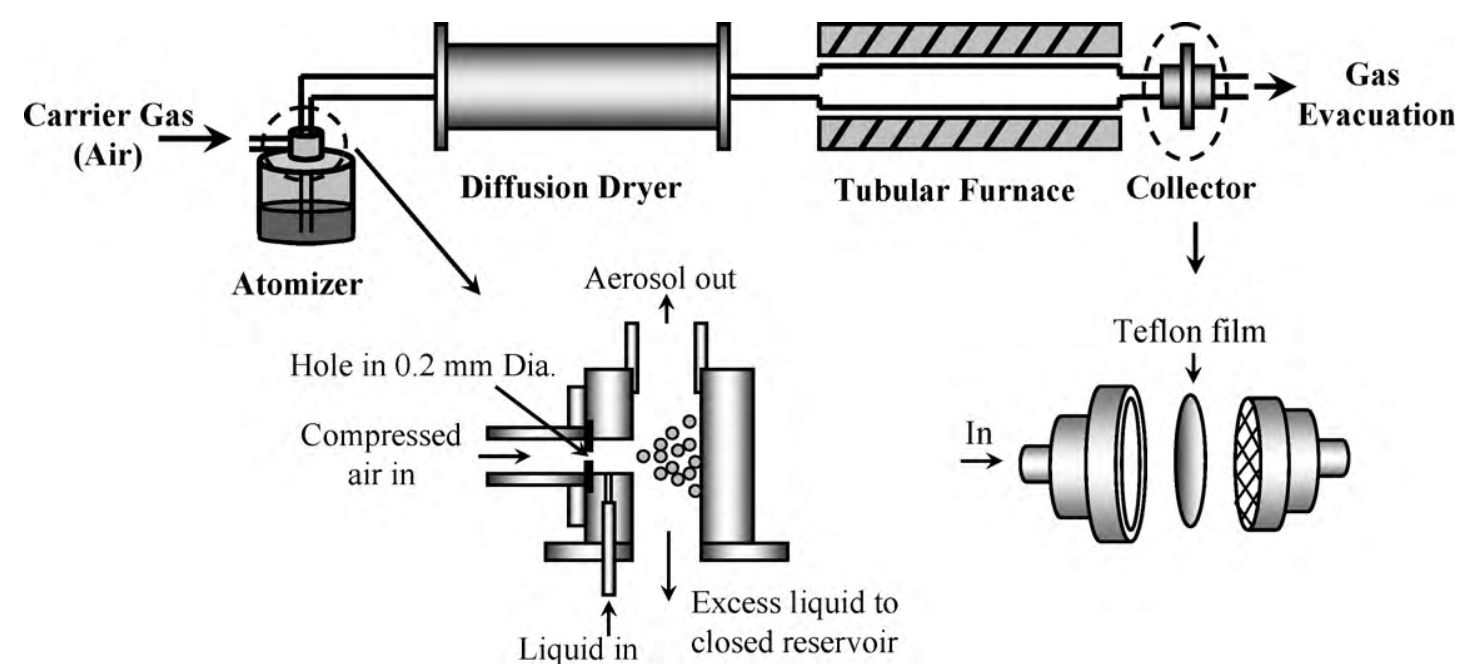

Fig. 1. Schematic diagram of the spray pyrolysis system.

In the current study, transition alumina with mesoporous structure was synthesized by alumisol spray pyrolysis without using structure-directing reagents. The crystalline structure, porosity, and morphology of the as-prepared alumina were well characterized, and the effects of certain crucial preparation parameters, such as preparation temperature, residence time, and precursor concentration, were investigated. In addition, the thermal stability of the mesoporous structure was also investigated, and a possible mesopore formation mechanism was proposed based on the results.

\section{Experimental}

\subsection{Particle synthesis}

The spray pyrolysis system consisted of a home-made atomizer, a diffusion dryer, a corundum tube located inside a tubular furnace (SK-2.5-14K, Huabei Experiment Instrument, China), and a filter collector (Fig. 1). Precursor droplets were sprayed by expanding compressed air through the atomizer in which alumisol was stored. After passed through the diffusion dryer, these partly dried droplets were carried into the corundum tube housed inside the tubular furnace, and the resultant pyrolysate was finally collected by a filter sampler. The temperature of the tubular furnace was controlled and adjusted in the range of $500-1200^{\circ} \mathrm{C}$. Particle residence time in the furnace was controlled by varying the airflow rate from 0.4 to $3.0 \mathrm{~L} \mathrm{~min}^{-1}$, corresponding to a residence time of $5.97-0.80 \mathrm{~s}$.

A stable boehmite phase alumisol (AlOOH, Lot No. 2205, Kawaken Fine Chemicals Co., Ltd.) with an initial concentration of $10.0 \mathrm{wt} \%$, calculated according to $\mathrm{Al}_{2} \mathrm{O}_{3}$ content, was used as the precursor solution. Impurities in the alumisol, such as inorganic salts, were below the detection limit of ion chromatography (information from Kawaken Fine Chemicals Co., Ltd.). The $\mathrm{pH}$ value of the alumisol was 3.7 measured by a pH-meter (pHs25, Shanghai Leici Factory, China), and the viscosity was $4 \mathrm{mPa} s$ measured by an Ubbelohde viscometer (53210, Schoott, German). The alumisol concentrations in the experiments were $0.1,1.0$ and 10.0 wt\% (as $\mathrm{Al}_{2} \mathrm{O}_{3}$ content) and were diluted with deionized water $(18 \mathrm{M} \Omega)$.

\subsection{Post thermal treatment}

To investigate the thermal stability of the mesoporous structure, post calcination in a ceramic fiber muffle furnace (TM0614P, Michem, China) was carried out by heating the prepared particles (from $10.0 \mathrm{wt} \%$ alumisol at $1000^{\circ} \mathrm{C}$ with a carrier airflow rate of $3.0 \mathrm{Lmin}^{-1}$ ) at 300,600 and $900^{\circ} \mathrm{C}$ for $30 \mathrm{~h}$, respectively, with a heating rate of $5^{\circ} \mathrm{C} \mathrm{min}-1$ from $25^{\circ} \mathrm{C}$ to the corresponding calcination temperature.
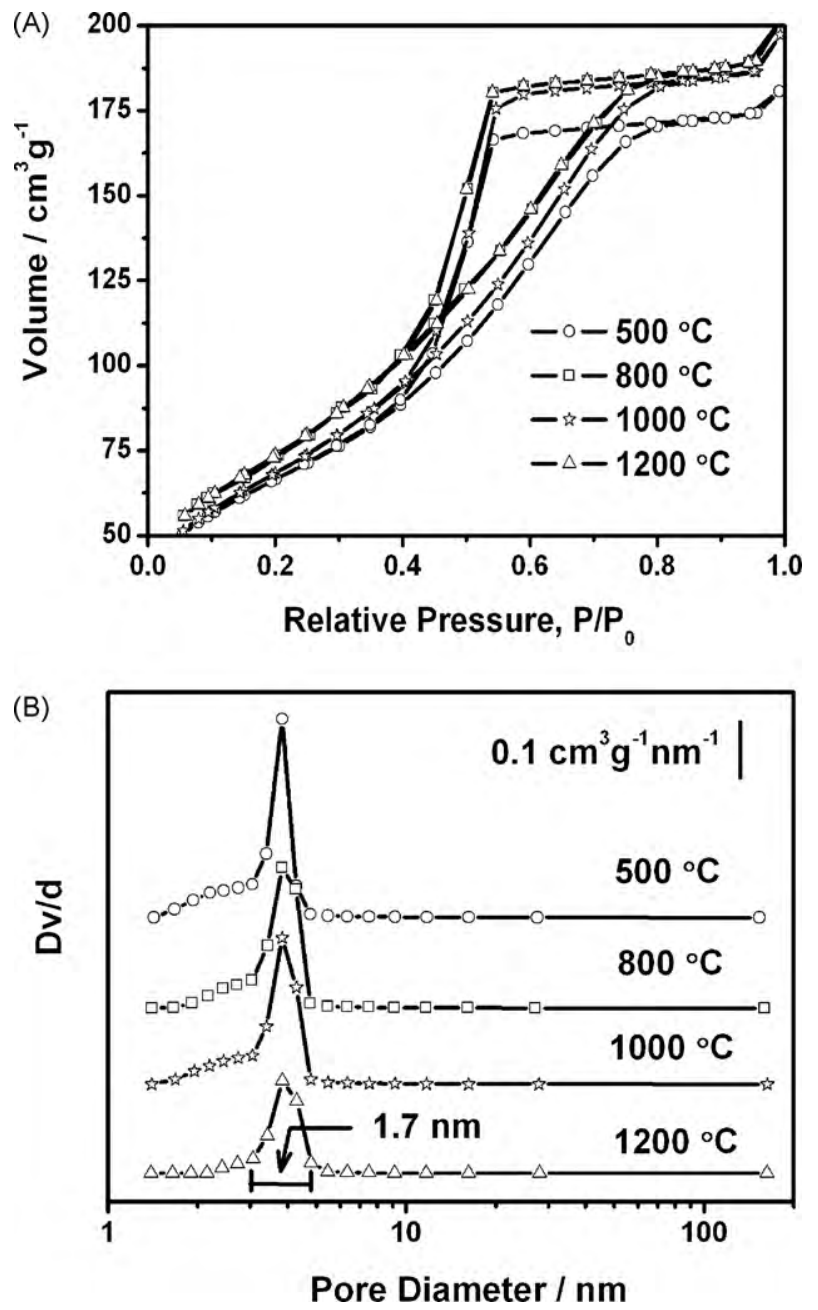

Fig. 2. (A) The adsorption-desorption isotherms and (B) the corresponding pore size distributions of the samples prepared from $10.0 \mathrm{wt} \%$ alumisol at different preparation temperature with a carrier airflow rate of $3.0 \mathrm{~L} \mathrm{~min}^{-1}$. 

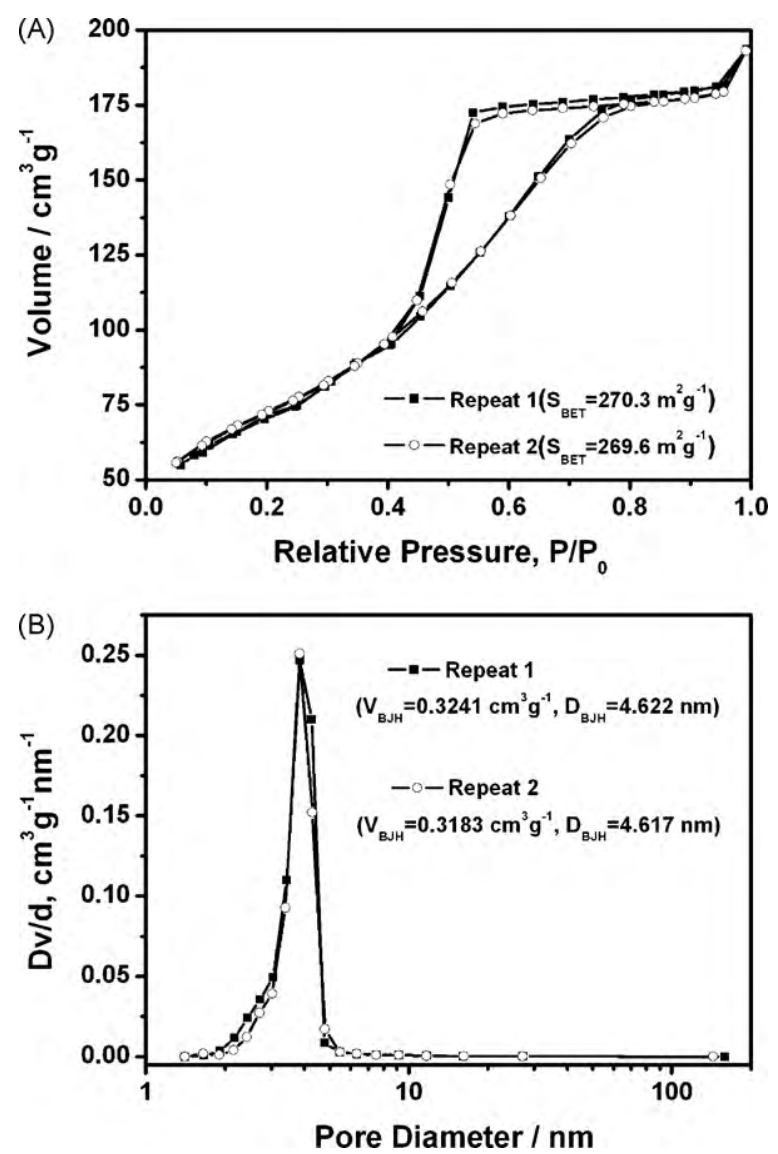

Fig. 3. The reproducibility of mesoporous structure. (A) The adsorption-desorption isotherms and (B) the corresponding pore size distributions of samples (10.0 wt\% alumisol at $1000^{\circ} \mathrm{C}$ with carrier airflow rate $3.0 \mathrm{~L} \mathrm{~min}^{-1}$ ) collected from tow batches.

\subsection{Characterization of prepared particles}

The surface area and pore structure (volume and size) of the samples were determined with a physisorption analyzer (Autosorb-1C-TCD, Quantachrome, USA) by $\mathrm{N}_{2}$ adsorptiondesorption at $-196^{\circ} \mathrm{C}$. The surface area $\left(S_{\mathrm{BET}}\right)$ was determined by applying the Brunauer-Emmmett-Teller (BET) method to the adsorption isotherm in the range of $0.05-0.35$. The pore volume $\left(V_{\mathrm{BJH}}\right)$ and the pore diameter $\left(D_{\mathrm{BJH}}\right)$ were determined by the Barrett-Joyner-Halenda (BJH) equation from the desorption isotherm. The instrument errors of $S_{\mathrm{BET}}, V_{\mathrm{BJH}}$, and $D_{\mathrm{BJH}}$ determined by at least three tests for one sample were $\pm 0.76 \%, \pm 1.1 \%$, and $\pm 0.03 \%$, respectively.

The crystalline structure of the samples was determined by a powder X-ray diffractometer (XRD; X'Pert PRO, PANalytical, Netherlands) using $\mathrm{Cu} \mathrm{K \alpha}(\lambda=1.54 \AA)$ radiation at $40 \mathrm{kV}$ and $40 \mathrm{~mA}$ with scans from 10 to $90^{\circ}$ in increments of $0.026^{\circ}$. Peak positions and relative intensities were characterized by comparison with ICDD files.

Infrared experiments were performed with a Fourier transform infrared spectrometer (FT-IR; 6700, Thermo Nicolet, USA). All spectra reported here were recorded at a resolution of $4 \mathrm{~cm}^{-1}$ for 100 scans.

The particle size distributions of samples were measured on line using a scanning mobility particle sizer (SMPS; TSI 3936, USA) consisting of a nano differential mobility analyzer (DMA; TSI 3085, USA) and a condensation particle counter (CPC; TSI 3025A, USA). The particle size data from the SMPS were taken over the size range from 10 to $700 \mathrm{~nm}$.
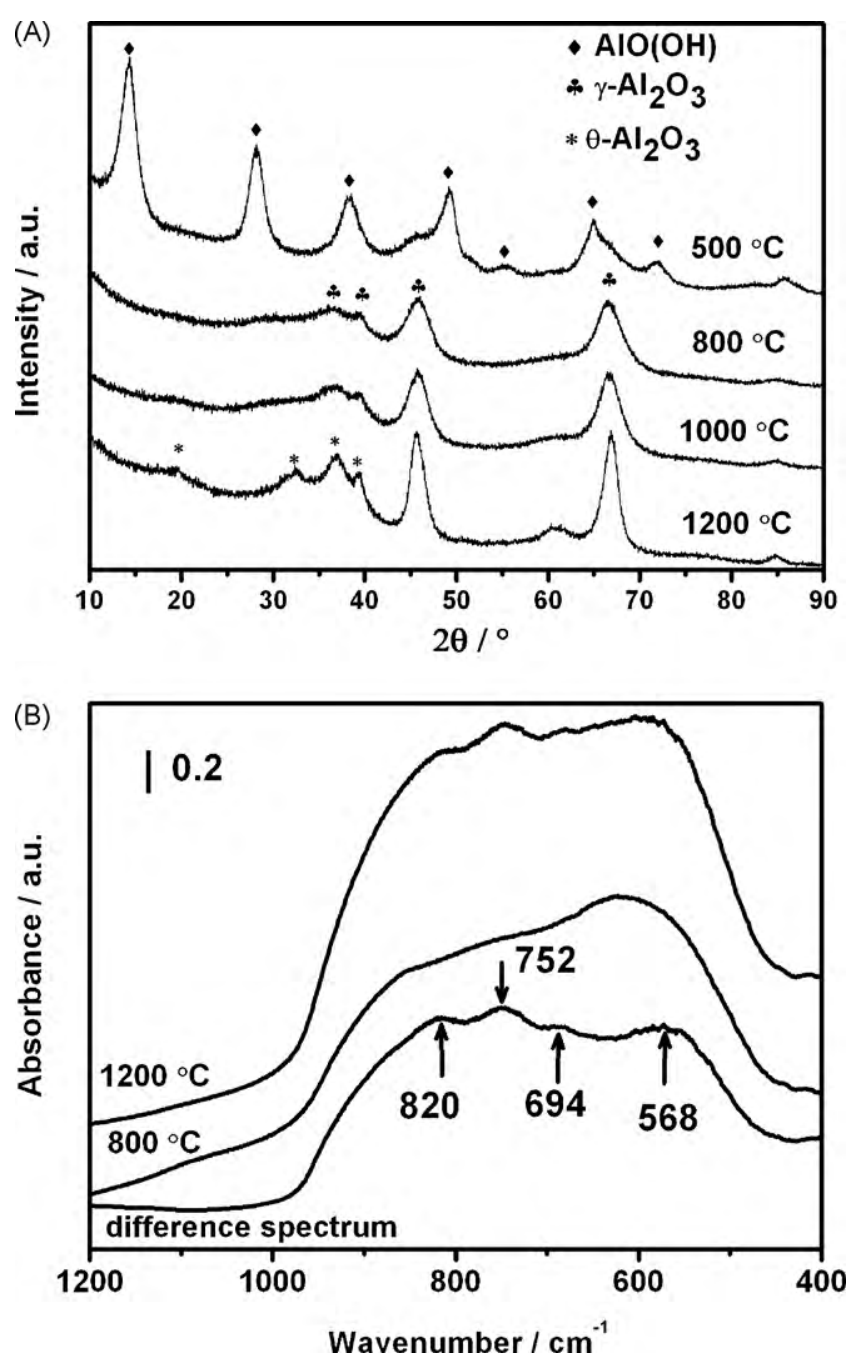

Fig. 4. (A) XRD patterns of alumina particles prepared from $10.0 \mathrm{wt} \%$ alumisol, carrier airflow rate of $3.0 \mathrm{~L} \mathrm{~min}^{-1}$, and different temperature from 500 to $1200{ }^{\circ} \mathrm{C}$. (B) FTIR spectra of samples obtained at 1200 and $800^{\circ} \mathrm{C}$, and the difference spectrum between them.

The morphologies of samples were examined by: 1 . Scanning electron microscopy (SEM; SUPRA 55, NEISS, German) at $10 \mathrm{kV}$; 2. High resolution transmission electron microscopy accompanied with an X-ray energy dispersive spectroscopy (HRTEM-EDS; JEOL JEM-2011, Tokyo, Japan) at $200 \mathrm{kV}$; 3. Transmission electron microscopy (TEM; H-7500, Hitachi, Japan) with an accelerating voltage of $40 \mathrm{kV}$.

\section{Results and discussion}

\subsection{Effect of preparation temperature}

Fig. 2A shows the $\mathrm{N}_{2}$ adsorption-desorption isotherms for the samples prepared at $500,800,1000$, and $1200^{\circ} \mathrm{C}$ with $10.0 \mathrm{wt} \%$ alumisol and a $3.0 \mathrm{~L} \mathrm{~min}^{-1}$ carrier airflow rate. All isotherms exhibited a type-IV curve with a H2-type hysteresis loop, characteristic of mesoporous particles with interconnected pore networks [31-33]. Fig. $2 \mathrm{~B}$ shows the pore size distributions obtained from the $\mathrm{BJH}$ method on the basis of the desorption data. The pore sizes of these alumina samples ranged from 3.0 to $4.7 \mathrm{~nm}$, with the major pore size approximately $3.85 \mathrm{~nm}$.

The BET surface areas and pore structure parameters (volume and size) of the samples are summarized in Table 1. Monotonous decrease of the BET surface area and the pore volume occurred 

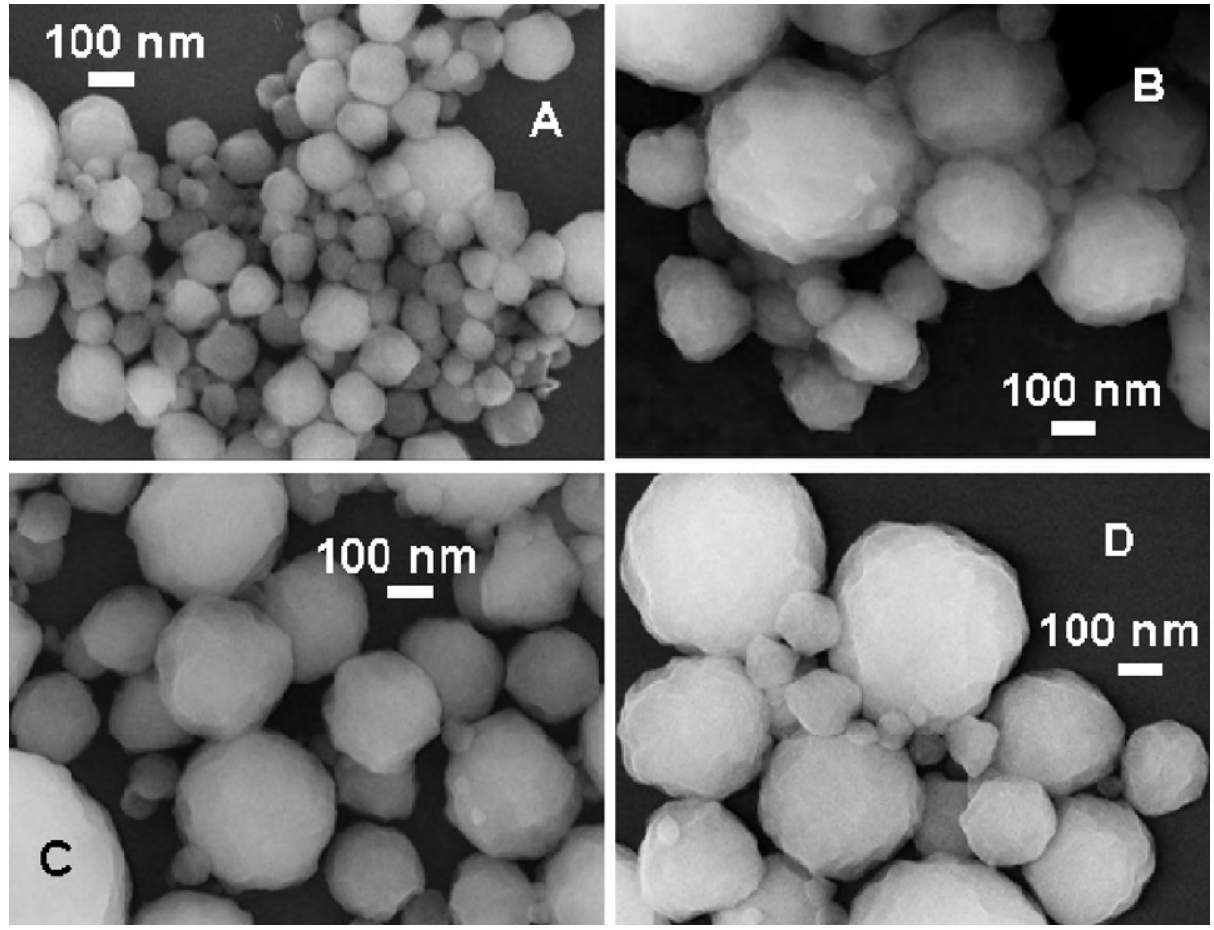

Fig. 5. SEM micrographs of samples produced from $10.0 \mathrm{wt} \%$ alumisol with temperatures from 500 to $1200^{\circ} \mathrm{C}$.

with an increase in preparation temperature. The pore diameter increased from 4.100 to $4.622 \mathrm{~nm}$ when the temperature rose from 500 to $1000^{\circ} \mathrm{C}$, but decreased to $3.843 \mathrm{~nm}$ at a preparation temperature of $1200^{\circ} \mathrm{C}$. According to previous research [34], the dilation of pores always contributes to a decrease in surface area and pore volume and a simultaneous increase in pore diameter. In this study, a similar phenomenon was exhibited for samples prepared at 500, 800 and $1000^{\circ} \mathrm{C}$. For the sample prepared at $1200^{\circ} \mathrm{C}$, however, the pore diameter decreased together with the BET surface area and pore volume, which may be due to pore structure collapse at this temperature. It was reported that specific surface area loss during heating is related to phase transformation [35]. The BET surface area was reduced by $12.5 \%$ with an increase in temperature from 500 to $800^{\circ} \mathrm{C}$ and by $41.7 \%$ from 1000 to $1200^{\circ} \mathrm{C}$, implying that phase transformations took place from 500 to $800^{\circ} \mathrm{C}$ and from 1000 to $1200^{\circ} \mathrm{C}$.

The reproducibility of mesoporous structure was verified by repeated BET measurements of samples prepared at the same condition but collected from different batches. For example, the pore structure of two batches of sample prepared from $10.0 \mathrm{wt} \%$ alumisol at $1000^{\circ} \mathrm{C}$ with carrier airflow rate $3.0 \mathrm{~L} \mathrm{~min}^{-1}$ is shown in Fig. 3. It illustrates that the difference of the adsorption-desorption isotherms and the corresponding pore size distributions between two batches was negligible. Therefore, the preparation of mesoporous alumina via spray pyrolysis method is consistent and reproducible.

Table 1

The specific surface area and pore structure (volume and size) of alumina particles prepared from $10.0 \mathrm{wt} \%$ alumisol, carrier airflow rate of $3.0 \mathrm{~L} \mathrm{~min}^{-1}$, and different preparation temperature.

\begin{tabular}{clll}
\hline Preparation temperature & $S_{\mathrm{BET}}\left(\mathrm{m}^{2} \mathrm{~g}^{-1}\right)$ & $V_{\mathrm{BJH}}\left(\mathrm{cm}^{3} \mathrm{~g}^{-1}\right)$ & $D_{\mathrm{BJH}}(\mathrm{nm})$ \\
\hline $500^{\circ} \mathrm{C}$ & 327.1 & 0.3411 & 4.100 \\
$800^{\circ} \mathrm{C}$ & 286.3 & 0.3253 & 4.367 \\
$1000^{\circ} \mathrm{C}$ & 270.3 & 0.3241 & 4.622 \\
$1200^{\circ} \mathrm{C}$ & 157.7 & 0.2430 & 3.843 \\
\hline
\end{tabular}

One of the major restrictions in the application of conventional alumina is deactivation by coke formation and pore plugging. The deactivation rate is greatly enhanced by wider pore size distribution and additional micropores contributing to the specific surface area [15]. With narrow pore size distribution, uniform pore structure, and high surface area, the as-prepared alumina from the present study has great application potential within the catalysis field.

The X-ray diffraction spectra of particles prepared at 500, 800, 1000 and $1200^{\circ} \mathrm{C}$ are displayed in Fig. 4A. It shows that for the sample prepared at $500^{\circ} \mathrm{C}$, the boehmite phase (ICDD no. 83-2384) of the alumisol precursor was maintained. The main peaks at $2 \theta$ $36.3^{\circ}, 39.5^{\circ}, 45.9^{\circ}$, and $66.9^{\circ}$ due to $\gamma-\mathrm{Al}_{2} \mathrm{O}_{3}$ (ICDD no. 49-0134) were, however, observed in the spectra of samples prepared at 800 , 1000 and $1200^{\circ} \mathrm{C}$. This indicates that the thermal decomposition of boehmite was combined with the bulk phase transition of alumina as the preparation temperature increased above $800^{\circ} \mathrm{C}$. For the sample prepared at $1200^{\circ} \mathrm{C}$, some peaks at $19.5^{\circ}, 32.6^{\circ}, 36.9^{\circ}$, and $39.4^{\circ}$ were also observed characteristic of $\theta-\mathrm{Al}_{2} \mathrm{O}_{3}$ (ICDD no. 23-1009). The formation of the $\theta$-phase was further confirmed by FTIR measurement, as shown in Fig. 4B. Although the spectra of the samples prepared at 1200 and $800^{\circ} \mathrm{C}$ showed some similarity, absorption bands at $568,694,752$, and $820 \mathrm{~cm}^{-1}$ in the difference spectrum between them clearly confirmed the existence of $\theta-\mathrm{Al}_{2} \mathrm{O}_{3}[36,37]$. As convincing support of the XRD results, the FTIR measurement confirmed that the surface and bulk phase transition from $\gamma-\mathrm{Al}_{2} \mathrm{O}_{3}$ to $\theta-\mathrm{Al}_{2} \mathrm{O}_{3}$ both took place at $1200^{\circ} \mathrm{C}$, although the formation of the $\theta$-phase was only in the beginning stage.

Several previous studies have reported on the transformation behavior of boehmite sol during heat treatment from room temperature to 1300 or $1400^{\circ} \mathrm{C}$ in air for several hours [38,39]. Results show that the boehmite phase persists until $200{ }^{\circ} \mathrm{C} ; \gamma-\mathrm{Al}_{2} \mathrm{O}_{3}$ appears at $400{ }^{\circ} \mathrm{C}$, and $\delta-\mathrm{Al}_{2} \mathrm{O}_{3}$ forms when the calcination temperature is between 400 and $600{ }^{\circ} \mathrm{C}$; $\delta$ - to $\theta-\mathrm{Al}_{2} \mathrm{O}_{3}$ transformation occurs at $1000^{\circ} \mathrm{C}$ and $\theta-\mathrm{Al}_{2} \mathrm{O}_{3}$ becomes the major phase at $1100^{\circ} \mathrm{C}$; $\theta$ - to well crystallized $\alpha-\mathrm{Al}_{2} \mathrm{O}_{3}$ takes place at $1200^{\circ} \mathrm{C}$. Thus, the 

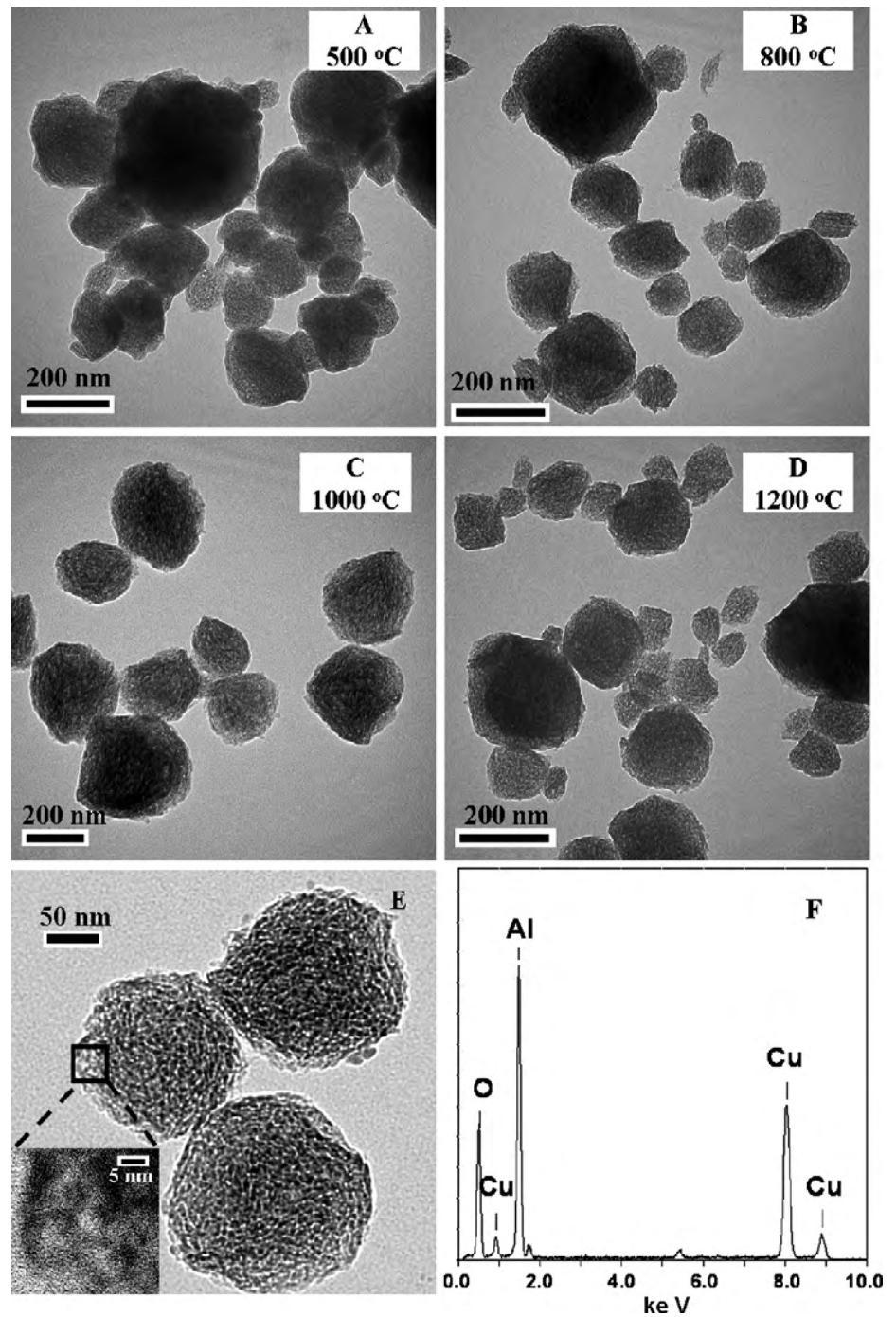

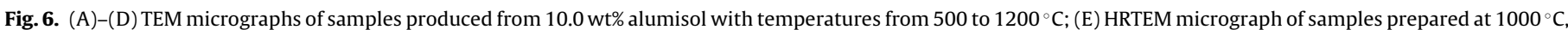
and $(\mathrm{F})$ the corresponding EDS analysis (Cu grid was used as the sample holder and reflected in the analysis result).

dehydration and subsequent crystallization of boehmite sol can be described as: boehmite $\rightarrow \gamma-\mathrm{Al}_{2} \mathrm{O}_{3} \rightarrow \delta-\mathrm{Al}_{2} \mathrm{O}_{3} \rightarrow \theta-\mathrm{Al}_{2} \mathrm{O}_{3} \rightarrow \alpha-$ $\mathrm{Al}_{2} \mathrm{O}_{3}$. A similar transformation sequence was observed in the present study, although the $\gamma$ - and $\theta$-phase formation temperatures (800 and $1200^{\circ} \mathrm{C}$, respectively) were higher than the previously reported values $\left(400\right.$ and $1000^{\circ} \mathrm{C}$ ), and the formation of $\alpha-\mathrm{Al}_{2} \mathrm{O}_{3}$ did not occur at $1200^{\circ} \mathrm{C}$. The absence of $\alpha-\mathrm{Al}_{2} \mathrm{O}_{3}$ and the shift of phase transformation temperatures may be due to the short residence time here $(0.80 \mathrm{~s})$. It has been reported that prolonged residence time affects phase transformation behavior [40], which will be discussed in Section 3.2.

SEM micrographs in Fig. 5 show that all particles were highly spherical-shaped without aggregating to irregular particles, even when the preparation temperature increased to $1200^{\circ} \mathrm{C}$. The particle surface was a little coarse and showed a pleated morphology. TEM and HRTEM micrographs of particles are presented in Fig. 6. It clearly shows that an interconnected worm-like pore network was involved in the porous spherical particles. As shown in the inset image of Fig. 6E, the microscopic voids with a diameter of 4-5 nm were due to the presence of mesopores, which conforms to the $\mathrm{N}_{2}$ adsorption-desorption analysis results. Moreover, the EDS analysis in Fig. $6 \mathrm{~F}$ confirms the exclusive presence of the constitutive elements ( $\mathrm{Al}$ and $\mathrm{O}$ ) as well as high compositional

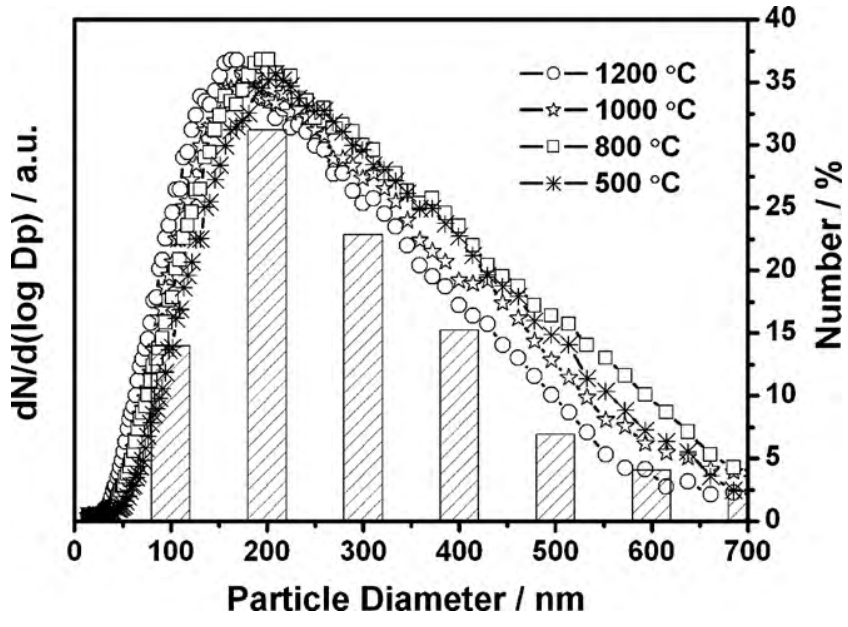

Fig. 7. Size distributions of prepared particles. Data presented as line and symbol curves (left $x$-axis) were SMPS results of particles prepared from $10.0 \mathrm{wt} \%$ alumisol with temperatures from 500 to $1200^{\circ} \mathrm{C}$. Data showed as column graph (right $x$-axis) was the size distribution of particles prepared at $1000^{\circ} \mathrm{C}$ determined by counting particles in representative SEM micrographs. 


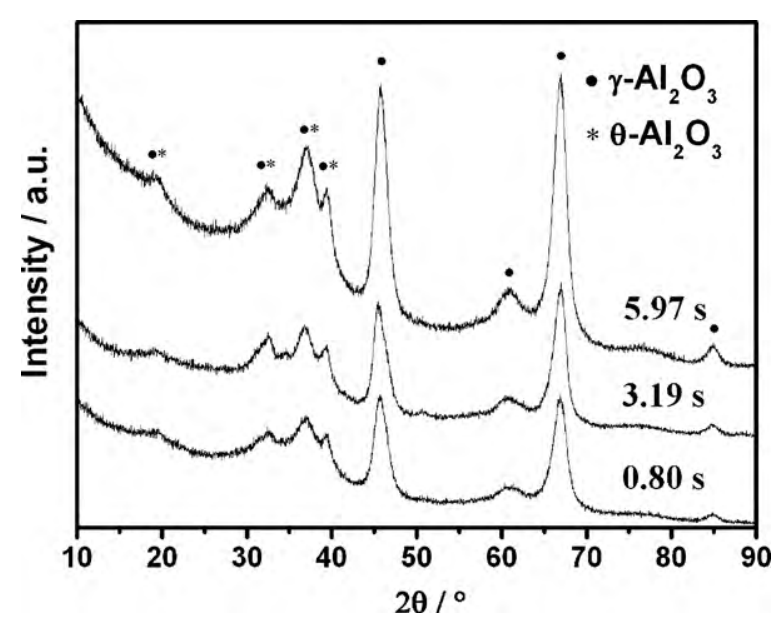

Fig. 8. XRD patterns of alumina particles prepared from $1.0 \mathrm{wt} \%$ alumisol at $1200^{\circ} \mathrm{C}$, with different residence time controlled by varying the airflow rate from 0.4 to 3.0 $\mathrm{Lmin}^{-1}$.

uniformity. Previous research has demonstrated that some watersoluble metal salts, such as nitrates, chlorides, and sulfates, may introduce impurities that have an adverse effect on subsequent processing and the properties of products [41]. The high purity of alumina prepared in this present study indicates that alumisol is an optimal precursor in the synthesis of alumina using spray pyrolysis.

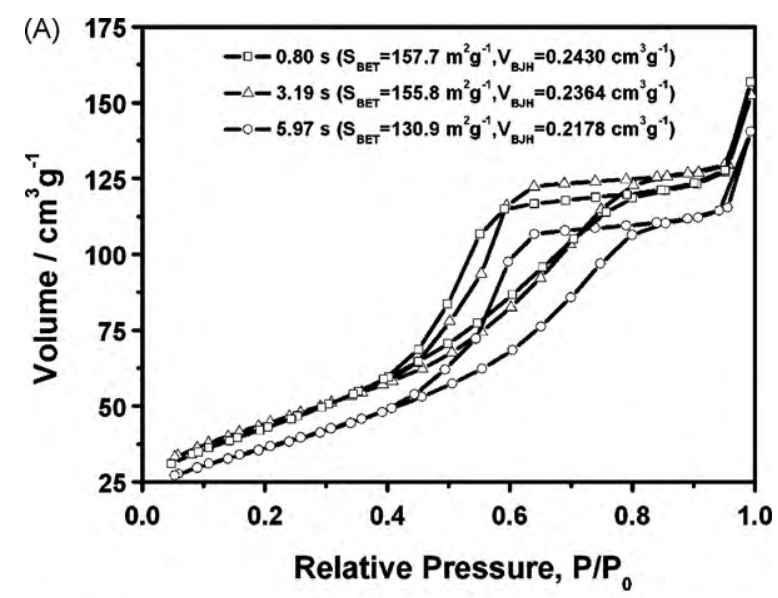

(B)

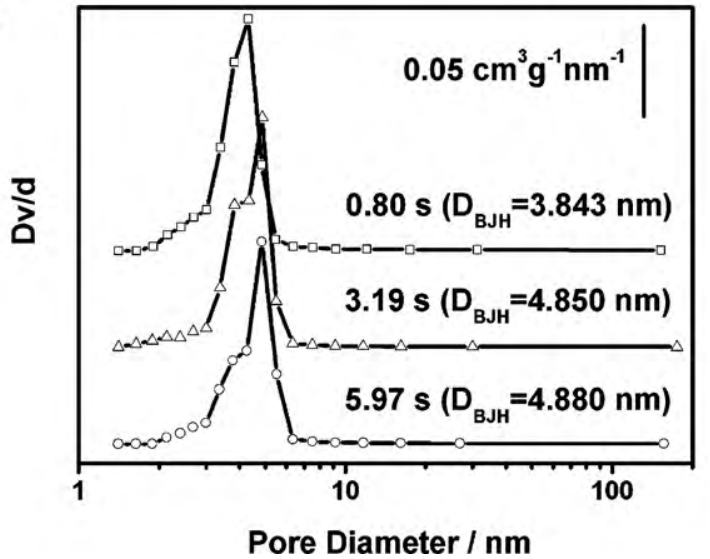

Fig. 9. Effect of residence time on (A) the adsorption-desorption isotherms and (B) the corresponding pore size distributions of particles prepared from $1.0 \mathrm{wt} \%$ alumisol at $1200^{\circ} \mathrm{C}$, and a carrier airflow rate of $0.4-3.0 \mathrm{~L} \mathrm{~min}^{-1}$.
Representative SEM graphs of particles prepared at $1000^{\circ} \mathrm{C}$ were selected to determine the size distribution by counting the particle size (Fig. 7, column graph). More than 800 particles were counted to obtain the number concentration result. The particle size distributions of prepared alumina were also measured by online SMPS analysis (Fig. 7, line and symbol curves), which was in good agreement with the result obtained from SEM micrographs. In addition, the SMPS results show that alumina particles prepared at different temperature exhibited similar size distributions. It implies that temperature has minor effect on the particle size distribution, which is similar to the result of Kim et al. [24]. Meanwhile, it is interest to notice that although the particle sizes distributed in a comparatively broad diameter range, the mesopore size distributions were still narrow. It indicates that the change of particle diameter has no significant effect on the mesoporous structure of prepared particles.

\subsection{Effect of residence time}

As discussed above, while the phase transformation from $\gamma$ $\mathrm{Al}_{2} \mathrm{O}_{3}$ to $\theta-\mathrm{Al}_{2} \mathrm{O}_{3}$ occurred at $1200^{\circ} \mathrm{C}$, the $\theta$-phase was not well defined due to limited preparation temperature. The residence time at $1200^{\circ} \mathrm{C}$ was, therefore, prolonged to investigate its influence on the phase transformation behavior of prepared alumina, as residence time is considered an important determinant of crystallinity [40]. The residence time at $1200^{\circ} \mathrm{C}$ was increased from 0.08 to $5.97 \mathrm{~s}$ by changing the flow rate from 3.0 to $0.4 \mathrm{~L} \mathrm{~min}^{-1}$. Further increases

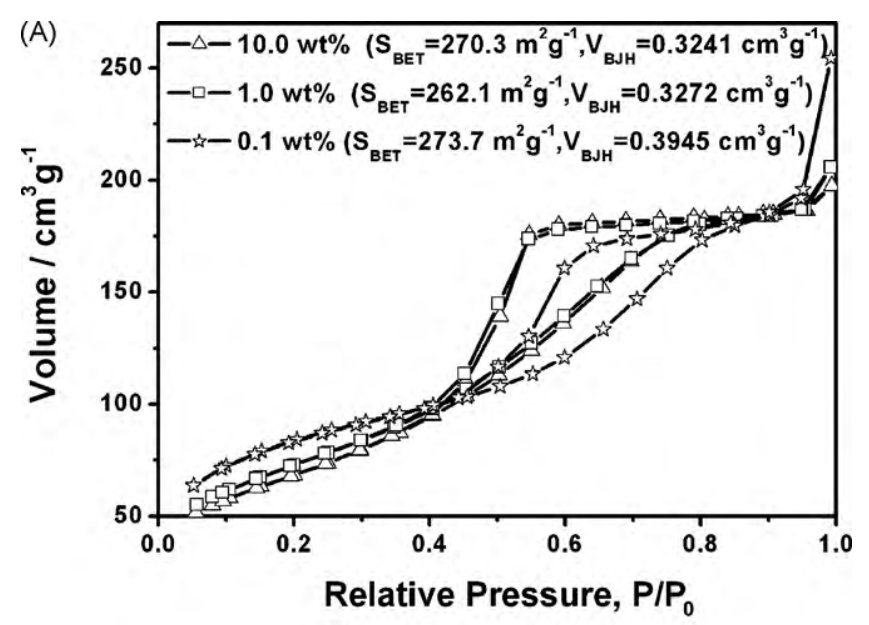

(B)

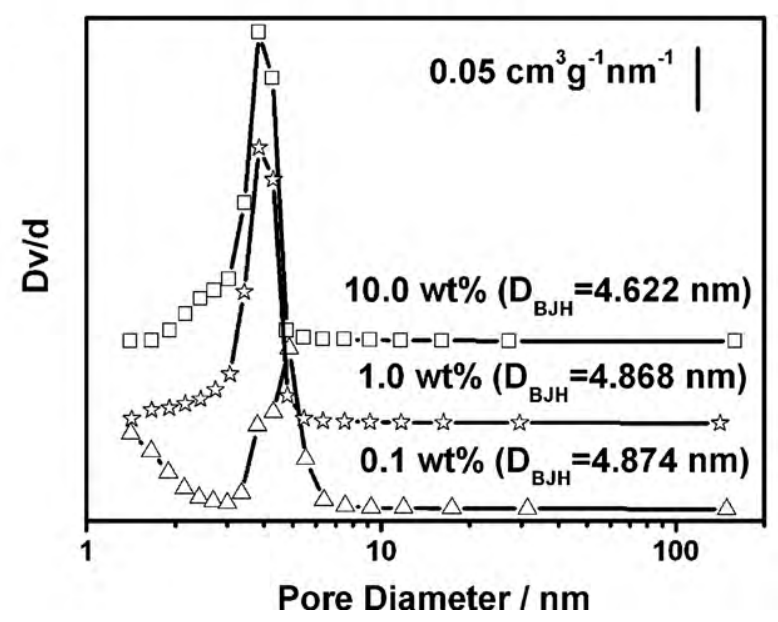

Fig. 10. (A) The adsorption-desorption isotherms and (B) the corresponding pore size distributions of the particles produced from 10.0, 1.0 and $0.1 \mathrm{wt} \%$ alumisol at $1000^{\circ} \mathrm{C}$, with a carrier airflow rate of $3.0 \mathrm{~L} \mathrm{~min}^{-1}$. 

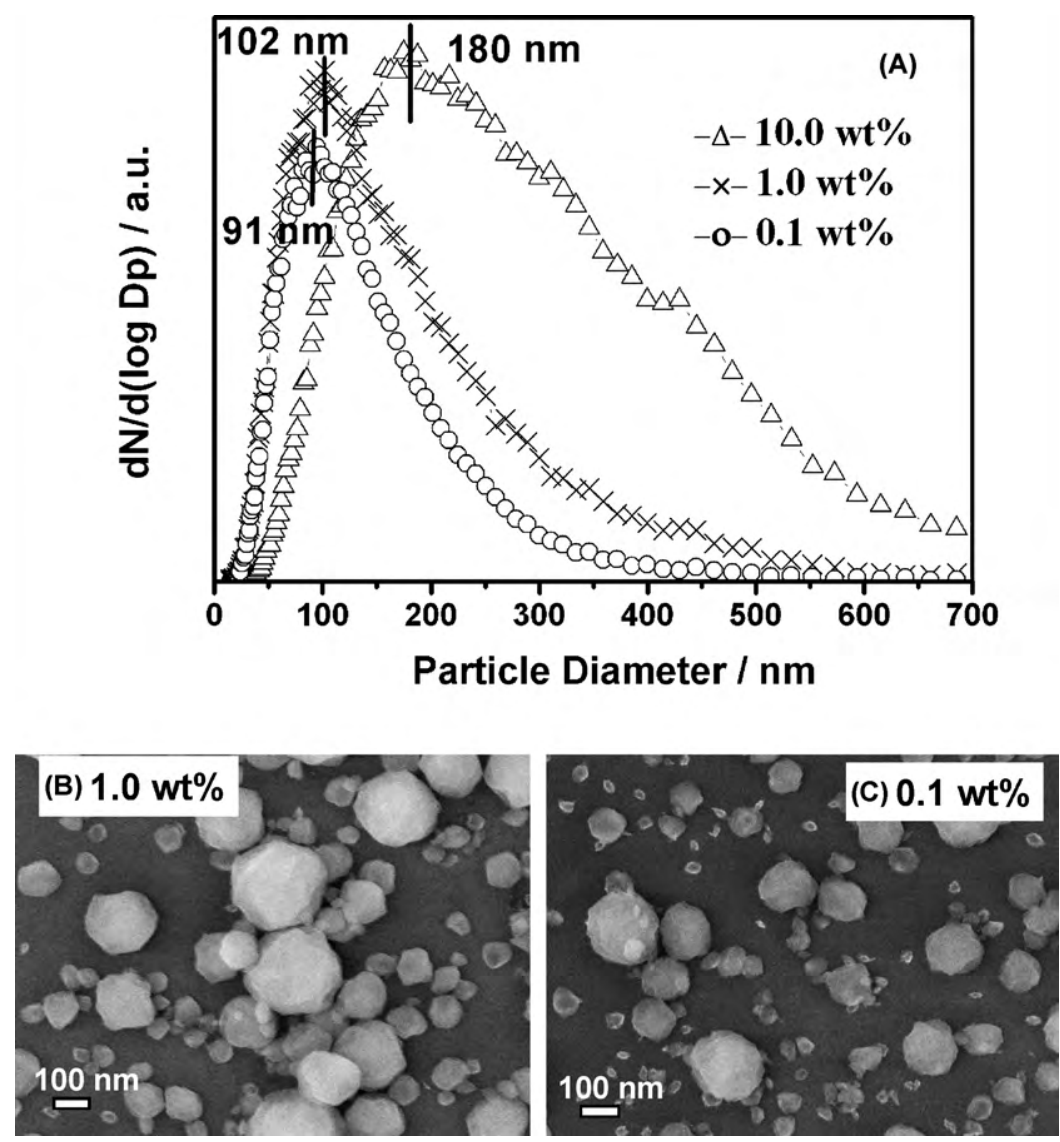

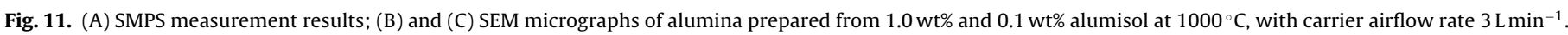

in residence time were not available due to the minimum flow rate required for atomization. In addition, the relatively high viscosity ( $4 \mathrm{mPa}$ ) of $10.0 \mathrm{wt} \%$ alumisol restricted atomization at low flow rates. The original alumisol was, therefore, diluted to $1.0 \mathrm{wt} \%$ to ensure the spray process.

The XRD patterns of particles prepared with different residence time (Fig. 8) show that all samples were a mixture of $\gamma-\mathrm{Al}_{2} \mathrm{O}_{3}$ (ICDD no. 49-0134) and $\theta-\mathrm{Al}_{2} \mathrm{O}_{3}$ (ICDD no. 23-1009), in which $\gamma-\mathrm{Al}_{2} \mathrm{O}_{3}$ was the dominant phase. However, sharper diffraction peaks with longer residence time implies that crystallinity was effectively promoted by prolonged residence time. Caiut et al. [28] have reported that short residence time (a few seconds) in the hot zone of the spray pyrolysis process restricts the complete transformation of boehmite to $\gamma-\mathrm{Al}_{2} \mathrm{O}_{3}$. Results in the present study indicate that, in addition to preparation temperature, phase transformation is also determined by residence time.

The effect of residence time on the surface area and pore structure was studied and is shown in Fig. 9. As residence time was prolonged, $S_{\mathrm{BET}}$ and $V_{\mathrm{BJH}}$ decreased and $D_{\mathrm{BJH}}$ increased. Although the mesoporous structure remained unchanged (as shown in Fig. 9A), the prolonged calcination step could result in aggravating sinter, and eventually influence surface area and pore volume.

\subsection{Effect of alumisol concentration}

The close connection between the precursor solution and product properties of the spray pyrolysis process has attracted significant attention. The effect of precursor concentration on the porosity of prepared alumina was investigated in this study.

Three weight concentrations (10.0, 1.0 , and $0.1 \mathrm{wt} \%$ ) of alumisol were selected to investigate the influence of concentration on pore structure. As seen from Fig. 10, all particles presented an isotherm characteristic of mesoporous structure and had similar BET surface area, while pore volume and pore size increased with alumisol concentration. It should be noted that when the alumisol concentration was reduced to $0.1 \mathrm{wt} \%$, a bimodal pore size distribution (Fig. 10B) was shown to exist. Mesopores with a major pore size of approximately $4.87 \mathrm{~nm}$ and micropores smaller than $2 \mathrm{~nm}$ were both present.

A possible explanation for the formation of a bimodal pore distribution is proposed as follows: the droplets generated from $0.1 \mathrm{wt} \%$ alumisol formed particles with less $\mathrm{Al}_{2} \mathrm{O}_{3}$, which meant less $\mathrm{Al}_{2} \mathrm{O}_{3}$ contributed to the mesoporous framework of the final particle. Consequently, larger pores tended to form after the evaporation of water, while smaller pores tended to form after the collapse of the unstable framework structure, and a bimodal pore distribution occurred.

SEM micrographs of alumina prepared from different concentration (Fig. 11B, C, Fig. 5C) imply that although the spherical shape was remained, the regularity of morphology reduced due to the decrease in concentration. Meanwhile, it tended to produce smaller particles with reduced precursor concentration. As demonstrated by SMPS measurements in Fig. 11A, the major particle diameters were 180,102 and $91 \mathrm{~nm}$ for alumisol concentration of 10.0,1.0 and $0.1 \mathrm{wt} \%$, respectively. The results confirm that lower concentration conduces to smaller particles.

\subsection{Thermal stability}

Despite the wide use of mesoporous alumina for catalyst support, loss of surface area and porosity can occur when they are heated above $500^{\circ} \mathrm{C}[11,14]$. The thermal stability of mesoporous alumina represents, therefore, one of the key points in its potential application as a catalyst support. In this study, thermal treatments 

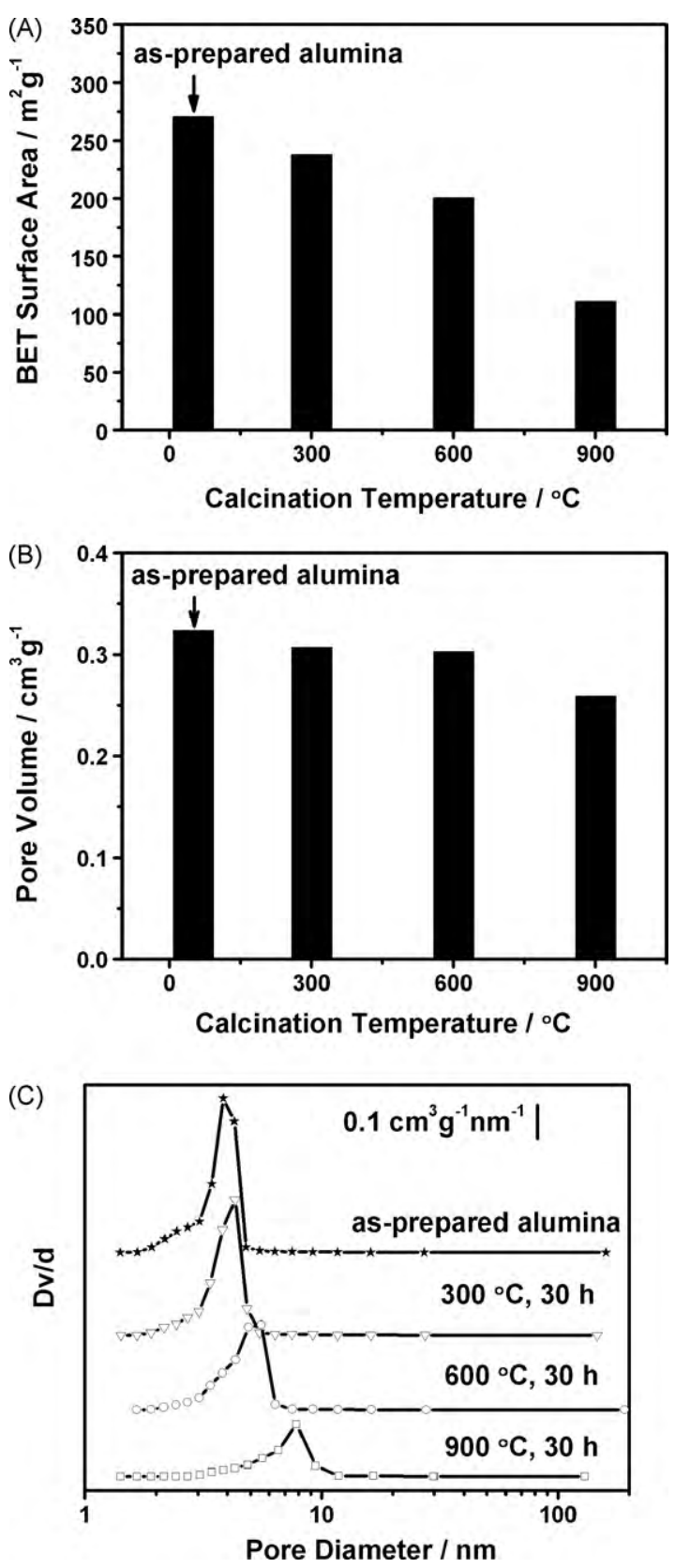

Fig. 12. (A) $S_{\mathrm{BET}}$, (B) $V_{\mathrm{BJH}}$ and (C) pore size distribution of alumina after post calcination at 300,600 , and $900^{\circ} \mathrm{C}$ for $30 \mathrm{~h}$, respectively. Alumina was prepared from $10.0 \mathrm{wt} \%$ alumisol at $1000^{\circ} \mathrm{C}$, with a carrier airflow rate of $3.0 \mathrm{~L} \mathrm{~min}^{-1}$.

in the temperature range of $300-900{ }^{\circ} \mathrm{C}$ were performed for $30 \mathrm{~h}$ over alumina prepared from $10.0 \mathrm{wt} \%$ alumisol at $1000^{\circ} \mathrm{C}$, with a carrier airflow rate of $3.0 \mathrm{~L} \mathrm{~min}^{-1}$. The influence of post calcination on the surface area, pore volume, and pore size distribution is shown in Fig. 12. The thermal treatment resulted in a decrease in BET surface area, as shown in Fig. 12A, but it should be noted that the surface areas were still greater than $200 \mathrm{~m}^{2} \mathrm{~g}^{-1}$ even after calcination at $600{ }^{\circ} \mathrm{C}$ for $30 \mathrm{~h}$, and greater than $100 \mathrm{~m}^{2} \mathrm{~g}^{-1}$ after calcination at $900^{\circ} \mathrm{C}$ for $30 \mathrm{~h}$. As the calcination temperature increased, the pore volume exhibited a slight decrease especially for samples calcinated at a temperature lower than $600^{\circ} \mathrm{C}$ (Fig. 12B), and meanwhile there is a slight increase in major pore size (Fig. 12C). This implies that post calcination had little effect on the pore structure of the as-prepared alumina particles. The mesoporous structure was not destroyed but maintained a uniform arrangement after thermal treatment. In addition, the XRD results in Fig. 13 demonstrate

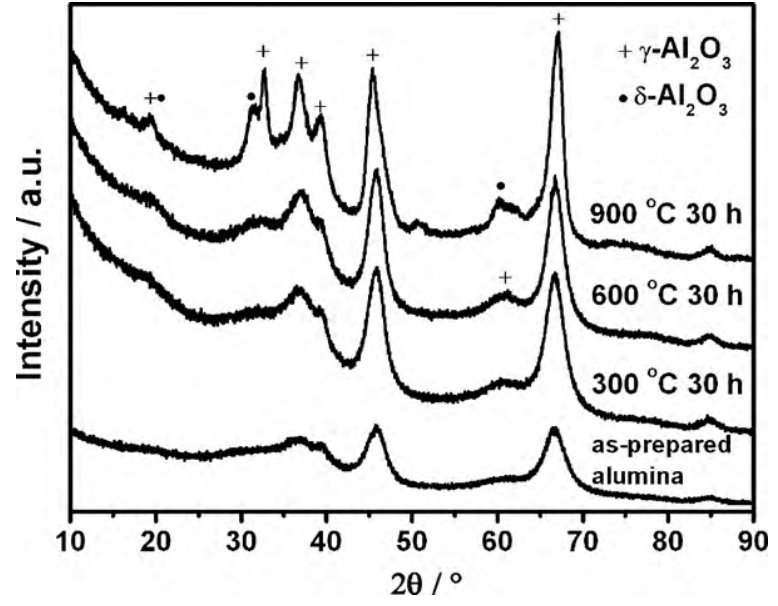

Fig. 13. XRD patterns of alumina calcinated at 300,600 and $900^{\circ} \mathrm{C}$ for $30 \mathrm{~h}$. Alumina was prepared from $10.0 \mathrm{wt} \%$ alumisol at $1000^{\circ} \mathrm{C}$, with a carrier airflow rate of 3.0 $\mathrm{Lmin}^{-1}$.

that the $\gamma$-phase was the major phase even after the calcination at $900^{\circ} \mathrm{C}$ for $30 \mathrm{~h}$, although some peaks at $19.5^{\circ}, 31.7^{\circ}$, and $60.2^{\circ}$ were observed as characteristic of $\delta-\mathrm{Al}_{2} \mathrm{O}_{3}$ (ICDD no. 46-1131). Both the $\mathrm{N}_{2}$ physisorption measurements and the XRD results indicate improved thermal stability of the as-prepared alumina, especially for the samples calcinated below $600^{\circ} \mathrm{C}$.

It has been reported that a possible approach to improve the thermal stability of metastable alumina is to dope the oxide framework with rare earth ( $\mathrm{La}, \mathrm{Ce}, \mathrm{Pr}, \mathrm{Nd}, \mathrm{Sm}, \mathrm{Yb}$ ) or alkaline earth (Ca, $\mathrm{Sr}, \mathrm{Ba}$ ) cations $[42,43]$. The addition of dopants, however, can complicate the preparation process and introduce impurities, which may limit industrial application. In the present study, thermal treatment had limited influence on the mesoporous structure, indicating significant potential applications of the as-prepared alumina in catalysis and other areas.

\subsection{Possible formation mechanism of mesopores}

The general spray pyrolysis process always involves four major steps [34,41,44,45]: generation of droplets from a precursor solution; shrinkage of droplet size due to evaporation; conversion of the precursor into oxides; and formation of solid particles. Evaporation of the solvent, diffusion of the solute, drying, pyrolysis, and sintering may occur in the formation of particles, among which solvent evaporation has been demonstrated to be critical to product porosity. Tsai et al. [44], for example, indicated that the formation of porous particles is due to a high solvent evaporation rate. Kim et al. [24] also proved that a higher rate of droplet evaporation could result in larger pore size and even create hollow-structured nanoporous particles.

In this study, alumisol was used as the precursor solution and water was the solvent. As shown in Fig. 14, the morphology of the suspended colloidal particles characterized by TEM was rod-shaped with a width of $2-3 \mathrm{~nm}$ and a length of $20 \mathrm{~nm}$. Water evaporated from the atomized alumisol droplets, resulting in the formation of viscous saturated droplets, in which cross-linked colloidal rods formed the porous structure framework. Further evaporation of water through the interspaces of the framework led to the formation of pores. When the droplet was completely dehydrated at high temperature, the conversion of the precursor into oxide occurred.

Preparation temperature and residence time play a crucial role in the evaporation rate of water during the saturation and dehydration step, and the high evaporation rate in this study was conducive to the formation of a uniform mesoporous structure. Precursor concentration determined the contribution of the aluminum precursor 


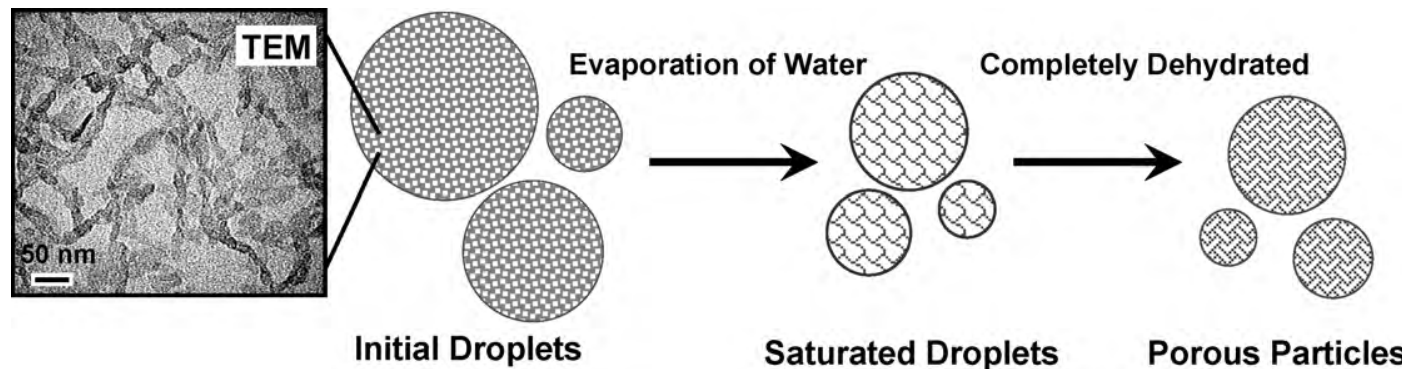

Fig. 14. Schematic diagram of the possible mesoporous particle formation process. The morphology of alumisol precursor is also presented in the TEM micrograph.

to the mesoporous framework in the final particles, and eventually affected the porosity. The detailed influence of the size and morphology of colloidal particles and the phase transformation of boehmite to $\theta-\mathrm{Al}_{2} \mathrm{O}_{3}$ on the porosity is worth further investigation.

\section{Conclusions}

Transition alumina was prepared by a one-step spray pyrolysis of alumisol precursor, without using structure-directing reagents. The prepared alumina exhibited a well-defined mesoporous structure with a narrow pore size distribution centered at approximately $3.85 \mathrm{~nm}$. Preparation temperature was a decisive factor in phase formation and porosity of the prepared alumina. Prolonged residence time effectively promoted the crystallinity of prepared alumina, but the subsequent sinter resulted in the formation of particles with smaller surface area, lower pore volume, and larger pores. Alumisol concentration was the main determinant of particle size, but it had little effect on the surface area. The present study highlighted the improved thermal stability of prepared alumina. Stabilization of the mesostructure, combined with high surface area and narrow pore size distribution, make the as-prepared alumina an ideal candidate for catalytic applications. Our approach also offers a flexible and economical opportunity for the industrial production of mesoporous alumina.

\section{Acknowledgments}

This research was financially supported by the National Natural Science Foundation of China (20937004, 50921064). The authors gratefully appreciate the kind help of Professor Jinian Shu in the design of the atomizer. Kawaken Fine Chemicals Co., Ltd. is also kindly acknowledged for providing the alumisol used in this research.

\section{References}

[1] H. Stumpf, A. Russell, J. Newsone, C. Tucker, Thermal transformations of aluminas and alumina hydrates, Ind. Eng. Chem. 42 (1950) 1398-1403.

[2] Y. Yeom, M. Li, A. Savara, W. Sachtler, E. Weitz, An overview of the mechanisms of NOx reduction with oxygenates over zeolite and $\gamma-\mathrm{Al}_{2} \mathrm{O}_{3}$ catalysts, Catal. Today 136 (2008) 55-63.

[3] R. Burch, J. Breen, F. Meunier, A review of the selective reduction of NOx with hydrocarbons under lean-burn conditions with non-zeolitic oxide and platinum group metal catalysts, Appl. Catal. B 39 (2002) 283-303.

[4] H. He, X.L. Zhang, Q. Wu, C.B. Zhang, Y.B. Yu, Review of $\mathrm{Ag} / \mathrm{Al}_{2} \mathrm{O}_{3}$-reductant system in the selective catalytic reduction of NOx, Catal. Surv. Asia 12 (2008) 38-55.

[5] Y. Zhang, G. Xiong, S. Sheng, W. Yang, Deactivation studies over $\mathrm{NiO} / \gamma-\mathrm{Al}_{2} \mathrm{O}_{3}$ catalysts for partial oxidation of methane to syngas, Catal. Today 63 (2000) 517-522.

[6] J. Koh, J. Lee, H. Kim, A. Cho, S. Moon, Correlation of the deactivation of $\mathrm{CoMo} / \mathrm{Al}_{2} \mathrm{O}_{3}$ in hydrodesulfurization with surface carbon species, Appl. Catal. B 86 (2009) 176-181.

[7] A. Borgna, T.F. Garetto, C.R. Apesteguía, Simultaneous deactivation by coke and sulfur of bimetallic $\mathrm{Pt}-\mathrm{Re}(\mathrm{Ge}, \mathrm{Sn}) / \mathrm{Al}_{2} \mathrm{O}_{3}$ catalysts for n-hexane reforming, Appl. Catal. A 197 (2000) 11-21.
[8] Z. Zhu, H. Liu, H. Sun, D. Yang, Surfactant assisted hydrothermal and thermal decomposition synthesis of alumina microfibers with mesoporous structure, Chem. Eng. J. 155 (2009) 925-930.

[9] P. Kim, Y. Kim, H. Kim, I.K. Song, J. Yi, Synthesis and characterization of mesoporous alumina with nickel incorporated for use in the partial oxidation of methane into synthesis gas, Appl. Catal. A 272 (2004) 157-166.

[10] J. Aguado, J.M. Escola, M.C. Castro, B. Paredes, Metathesis of 1-hexene over rhenium oxide supported on ordered mesoporous aluminas: comparison with $\mathrm{Re}_{2} \mathrm{O}_{7} / \gamma-\mathrm{Al}_{2} \mathrm{O}_{3}$, Appl. Catal. A 284 (2005) 47-57.

[11] L. Kaluža, M. Zdražil, N. Žilková, J. Čejka, High activity of highly loaded MoS hydrodesulfurization catalysts supported on organised mesoporous alumina, Catal. Commun. 3 (2002) 151-157.

[12] S. Lin, L. Wang, F.S. Xiao, Design and control of acidic strength in ordered mesoporous aluminosilicates by using preformed zeolite precursors, Stud. Surf. Sci. Catal. 154 (2004) 1513-1518.

[13] C. Márquez-Alvarez, N. Žilková, J. Pérez-Pariente, J. Čejka, Synthesis, characterization and catalytic applications of organized mesoporous aluminas, Catal. Rev. 50 (2008) 222-286.

[14] J. Čejka, Organized mesoporous alumina: synthesis, structure and potential in catalysis, Appl. Catal. A 254 (2003) 327-338.

[15] F. Vaudry, S. Khodabandeh, M.E. Davis, Synthesis of pure alumina mesoporous materials, Chem. Mater. 8 (1996) 1451-1464.

[16] Y. Kim, P. Kim, C. Kim, J. Yi, A novel method for synthesis of a $\mathrm{Ni} / \mathrm{Al}_{2} \mathrm{O}_{3}$ catalyst with a mesoporous structure using stearic acid salts, J. Mater. Chem. 13 (2003) 2353-2358.

[17] I. Balint, A. Miyazaki, Novel preparation method of well-defined mesostructured nanoaluminas via carbon-alumina composites, Micropor. Mesopor. Mater. 122 (2009) 216-222.

[18] M. Yada, H. Hiyoshi, K. Ohe, M. Machida, T. Kijima, Synthesis of aluminumbased surfactant mesophases morphologically controlled through a layer to hexagonal transition, Inorg. Chem. 36 (1997) 5565-5569.

[19] M. Yada, H. Kitamura, M. Machida, T. Kijima, Biomimetic surface patterns of layered aluminum oxide mesophases templated by mixed surfactant assemblies, Langmuir 13 (1997) 5252-5257.

[20] R. Strobel, A. Alfons, S.E. Pratsinis, Aerosol flame synthesis of catalysts, Adv. Powder Technol. 17 (2006) 457-480.

[21] R. Mueller, L. Mädler, S.E. Pratsinis, Nanoparticle synthesis at high production rates by flame spray pyrolysis, Chem. Eng. Sci. 58 (2003) 1969-1976.

[22] M.I. Martín, M.E. Rabanal, L.S. Gómez, J.M. Torralba, O. Milosevic, Microstructural and morphological analysis of nanostructured alumina particles synthesized at low temperature via aerosol route, J. Eur. Ceram. Soc. 28 (2008) 2487-2494.

[23] M.I. Martín, L.S. Gómez, O. Milosevic, M.E. Rabanal, Nanostructured alumina particles synthesized by the spray pyrolysis method: microstructural and morphological analyses, Ceram. Int. 36 (2010) 767-772.

[24] S.H. Kim, B.Y.H. Liu, M.R. Zachariah, Synthesis of nanoporous metal oxide particles by a new inorganic matrix spray pyrolysis method, Chem. Mater. 14(2002) 2889-2899.

[25] D. Sen, S. Mazumder, J.S. Melo, A. Khan, S. Bhattyacharya, S.F. D'Souza, Evaporation driven self-assembly of a colloidal dispersion during spray drying: volume fraction dependent morphological transition, Langmuir 25 (2009) 6690-6695.

[26] T. Hinklin, B. Toury, C. Gervais, F. Babonneau, J.J. Gislason, R.W. Morton, R.M. Laine, Liquid-feed flame spray pyrolysis of metalloorganic and inorganic alumina sources in the production of nanoalumina powders, Chem. Mater. $16(1)$ (2004) 21-30.

[27] A.I.Y. Tok, F.Y.C. Boey, X.L. Zhao, Novel synthesis of $\mathrm{Al}_{2} \mathrm{O}_{3}$ nano-particles by flame spray pyrolysis, J. Mater. Process. Technol. 178 (1-3) (2006) 270-273.

[28] J.M.A. Caiut, J. Dexpert-Ghys, Y. Kihn, M. Vérelst, H. Dexpert, S.J.L. Ribeiro, Y. Messaddeq, Elaboration of boehmite nano-powders by spray-pyrolysis, Powder Technol. 190 (1-2) (2009) 95-98.

[29] C. Boissière, L. Nicole, C. Gervais, F. Babonneau, M. Antonietti, H. Amenitsch, C. Sanchez, D. Grosso, Nanocrystalline mesoporous $\gamma$-alumina powders "UPMC1 material" gathers thermal and chemical stability with high surface area, Chem. Mater. 18 (2006) 5238-5243.

[30] J.H. Kim, K.Y. Jung, K.Y. Park, S.B. Cho, Characterization of mesoporous alumina particles prepared by spray pyrolysis of $\mathrm{Al}\left(\mathrm{NO}_{3}\right)_{2} \cdot 9 \mathrm{H}_{2} \mathrm{O}$ precursor: effect of CTAB and urea, Micropor. Mesopor. Mater. 128 (2010) 85-90. 
[31] P. Klobes, K. Meyer, R.G. Munro, Porosity and Specific Surface Area Measures for Solid Materials, National Institute of Standards and Technology, Special Publication 960-17, Washington, 2006.

[32] S.G. Deng, Y.S. Lin, Granulation of sol-gel-derived nanostructured alumina, AIChE J. 43 (1997) 505-514.

[33] K.S.W. Sing, D.H. Everett, R.A.W. Haul, L. Moscou, R.A. Piepotti, J. Rouquerol, T. Siemieniewska, Reporting phyisorption data for gas solid systems with special reference to the determination of surface area and porosity, Pure Appl. Chem. 57 (1985) 603-619.

[34] A. Gurav, T. Kodas, T. Pluym, Y. Xiong, Aerosol processing of materials, Aerosol Sci. Technol. 19 (1993) 411-452.

[35] T. Novaković, N. Radić, B. Grbića, V. Dondur, M. Mitrić, D. Randjelović, D. Stoychev, P. Stefanov, The thermal stability of porous alumina/stainless steel catalyst support obtained by spray pyrolysis, Appl. Surf. Sci. 255 (2008) 3049-3055.

[36] R. Rinaldi, U. Schuchardt, On the paradox of transition metal-free aluminacatalyzed epoxidation with aqueous hydrogen peroxide, J. Catal. 236 (2005) 335-345.

[37] A. Boumaza, L. Favaro, J. Lédion, G. Sattonnay, J.B. Brubach, P. Berthet, A.M. Huntz, P. Roy, R. Tétot, Transition alumina phases induced by heat treatment of boehmite: an X-ray diffraction and infrared spectroscopy study, J. Solid State Chem. 182 (2009) 1171-1176.

[38] S. Rossignol, C. Kappenstein, Effect of doping elements on the thermal stability of transition alumina, Int. J. Inorg. Mater. 3 (2001) 51-58.

[39] M. Chatterjee, D. Enkhtuvshin, B. Siladitya, D. Ganguli, Hollow alumina microspheres from boehmite sols, J. Mater. Sci. 33 (1998) 4937-4942.

[40] S.E. Pratsinis, Flame aerosol synthesis of ceramic powders, Prog. Energy Combust. Sci. 24 (1998) 197-219.

[41] G.L. Messing, S. Zhang, G.V. Jayanthi, Ceramic powder synthesis by spray pyrolysis, J. Am. Ceram. Sci. 76 (1993) 2707-2726.

[42] W.Zhang, T.J. Pinnavaia, Rare earth stabilization of mesoporous alumina molecular sieves assembled through an $\mathrm{N}^{\circ} \mathrm{I}^{\circ}$ pathway, Chem. Commun. 1998 (1998) 1185-1186.

[43] J.S. Church, N.W. Cant, D.L. Trimm, Stabilisation of aluminas by rare earth and alkaline earth ions, Appl. Catal. A 101 (1993) 105-116.

[44] S.C. Tsai, Y.L. Song, C.S. Tsai, C.C. Yang, W.Y. Chiu, H.M. Lin, Ultrasonic spray pyrolysis for nanoparticles synthesis, J. Mater. Sci. 39 (2004) $3647-$ 3657.

[45] K. Okuyama, I.W. Lenggoro, Preparation of nanoparticles via spray route, Chem Eng. Sci. 58 (2003) 537-547. 